\title{
Duodenal ulcers are a major cause of gastrointestinal bleeding after cardiac surgery
}

\author{
Frances Krawiec, MHSc, ${ }^{\mathrm{a}}$ Andrew Maitland, MB, ${ }^{\mathrm{a}}$ Qiuli Duan, MSc, ${ }^{\mathrm{b}}$ Peter Faris, PhD,
}

Paul J. Belletrutti, MD, ${ }^{\mathrm{c}}$ and William D. T. Kent, MD, $\mathrm{MSc}^{\mathrm{a}}$

\section{ABSTRACT}

Objective: To determine the incidence of gastrointestinal (GI) bleeding in patients after cardiac surgery, assess the perioperative risk factors, and determine the type of GI tract pathology associated with bleeding events.

Methods: At a tertiary referral hospital, all cardiac surgery patients having a postoperative GI bleed from April 2002 to March 2012 were identified. To determine bleeding etiology, only patients requiring endoscopy were included in the analysis. By retrospective review of 3 prospectively maintained databases, the incidence and independent predictors of GI bleeding, as well as endoscopic findings, were determined.

Results: Ninety-one GI bleeding events that required endoscopy were identified in 9017 patients. Those that bled were aged $71 \pm 12$ years, and $76 \%$ were men. Sixty-three percent of these patients had valve surgery and $37 \%$ had an isolated coronary artery bypass grafting. The overall incidence of GI bleeding was $1.01 \%$, with an upper GI source accounting for $78 \%$. Endoscopy data found a duodenal ulcer as the bleeding source in $71 \%$, whereas stress gastritis accounted for $8 \%$. Preoperative risk factors for bleeding included age $\geq 70$ years, ejection fraction $<35 \%$, congestive heart failure, cerebrovascular disease, chronic kidney disease, and gastrointestinal disease. A preoperative history of atrial fibrillation and anticoagulation with Coumadin also was associated with bleeding. Patients that bled had a 30-day mortality rate of $8.8 \%$, which was significantly greater than patients who did not bleed $(4.3 \% ; P=.03)$.

Conclusions: Clinical variables can be used to identify patients at high risk for GI bleeding after cardiac surgery. When GI bleeding occurs, the most common cause is duodenal ulceration, which has an association with Helicobacter pylori infection. These findings may provide an opportunity to initiate preoperative preventative strategies. (J Thorac Cardiovasc Surg 2017;154:181-8)

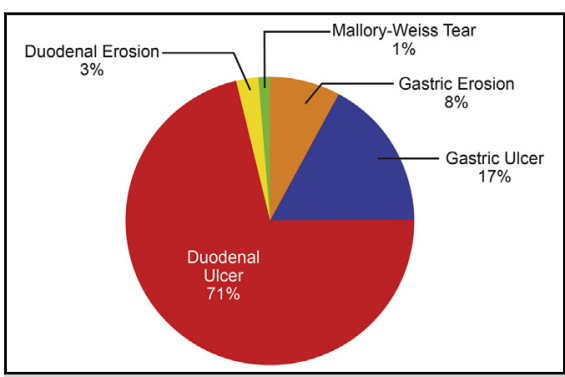

Endoscopic diagnoses of upper gastrointestinal bleeds.

\section{Central Message}

Endoscopic assessment of patients with gastrointestinal bleeding after cardiac surgery suggests the most common cause is peptic ulcer disease, commonly related to Helicobacter pylori infection.

\section{Perspective}

These data suggest the incidence of gastrointestinal bleeding after cardiac surgery is increasing. Preoperative identification of patient-related risk factors, together with testing and eradication of Helicobacter pylori, could have a significant mitigating effect on this high-risk complication.

See Editorial Commentary page 189

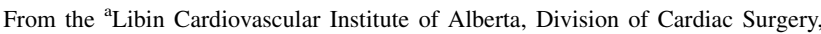
Foothills Medical Centre, ${ }^{b}$ Statistical Support Unit, Centre for Advancement of Health, and ${ }^{\mathrm{c}}$ Division of Gastroenterology and Hepatology, Department of Medicine, University of Calgary, Calgary, Alberta, Canada.

The Alberta Provincial Project for Outcomes Assessment in Coronary Heart Disease (APPROACH) database initially was funded with a grant from the W. Garfield Weston Foundation. The ongoing operation of the APPROACH project has been made possible by support from Alberta Health Services (Calgary Zone, Edmonton Zone), Libin Cardiovascular Institute of Alberta, and Mazankowski Alberta Heart Institute. The APPROACH initiative also has received contributions from Alberta Health and Wellness, and the following industry sponsors, Merck Frosst Canada Inc, Eli Lily Canada Inc, and Servier Canada Inc, to support the basic infrastructure of this cardiac registry initiative.

Received for publication May 11, 2016; revisions received Jan 20, 2017; accepted for publication Feb 7, 2017; available ahead of print March 7, 2017.

Address for reprints: William D. T. Kent, MD, MSc, Foothills Hospital, C800, 1403 29th St NW, Calgary, Alberta T2N 2T9, Canada (E-mail: william.kent@ahs.ca). $0022-5223 / \$ 36.00$

Copyright (c) 2017 by The American Association for Thoracic Surgery

http://dx.doi.org/10.1016/j.jtcvs.2017.02.012
}

Gastrointestinal (GI) bleeding is a complication of cardiac surgery that is associated with a high risk of mortality. ${ }^{1-3}$ Multiple reviews suggest that it may occur with an incidence of $0.2 \%$ to $2 \%$ in the postoperative period. ${ }^{1,2,4-12}$ Although this rate is lower than many postoperative complications, the associated mortality is not. In a comprehensive review of more than 150,000

Scanning this QR code will take you to a supplemental video for the article.

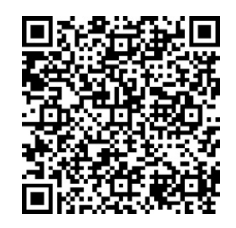




\section{Abbreviations and Acronyms \\ GI = gastrointestinal \\ NSAID $=$ nonsteroidal anti-inflammatory drug \\ PUD $=$ peptic ulcer disease}

patients, the incidence of postoperative GI bleeding was found to be $0.39 \%$, and the 30 -day mortality was $19 \% .^{13}$

Bleeding has been most commonly attributed to an upper GI source; however, specifics of the anatomic location and the characteristics of the bleeding lesion have not been well defined. ${ }^{2,8,10}$ Because of the physiologic stress of cardiac surgery, including full anticoagulation and cardiopulmonary bypass, it has been speculated that the most likely pathophysiologic mechanism is surgical stress-related mucosal breakdown, causing gastritis and gastric erosions. ${ }^{14}$ Alternatively, duodenal ulceration, commonly associated with peptic ulcer disease (PUD), has been found to be a common cause in some series. $^{4,5,12,15,16}$ In the general population, upper GI bleeding is caused most commonly by PUD and is manifested by bleeding duodenal ulcers. It is well recognized that PUD is highly associated with Helicobacter pylori infection, and it is not surprising that $H$ pylori infection has been identified as a preoperative risk factor for bleeding after cardiac surgery. ${ }^{17-20}$

The endoscopic findings of patients with GI bleeding after cardiac surgery are the best way to determine whether
PUD or stress-related mucosal breakdown is the more common pathology. This method could then facilitate preoperative identification of those at risk. For bleeding related to stress-related mucosal breakdown, prophylactic gastric acid suppression with proton pump inhibitors may be effective at reducing the risk. If PUD is a more common cause, however, preoperative testing and eradication of the $H$ pylori organism may have a significant mitigating effect.

For the present study, we hypothesized that the principle etiology of GI bleeding after cardiac surgery would be stress-related mucosal breakdown, causing gastritis and gastric erosions. We also anticipated that the overall incidence of GI bleeding has been increasing over time due to a greater risk profile of patients as well as an increasing use of oral anticoagulants and antiplatelet therapies.

\section{MATERIALS AND METHODS}

\section{Study Population}

As shown in Figure 1, there were 9017 patients who underwent cardiac surgery at the Foothills Medical Centre in Calgary, Alberta, Canada, between April 1, 2002, and March 1, 2012. The inclusion criteria for postoperative GI bleeding were defined as clinical evidence of GI bleeding, which required an endoscopic procedure. Because these criteria required the patient to have had endoscopic intervention, only major GI bleeds were captured. This was done to avoid the inclusion of small clinically insignificant bleeds, or bleeds that were misdiagnosed, such as patients with bloody nasogastric tube aspirate due to nasal trauma during nasogastric tube insertion.

Data from all patients undergoing cardiac surgery were reviewed, and those patients who met these criteria within 30 days of cardiac surgery were included in the analysis. Patients were excluded if the bleeding episode occurred preoperatively or if it presented more than 30 days

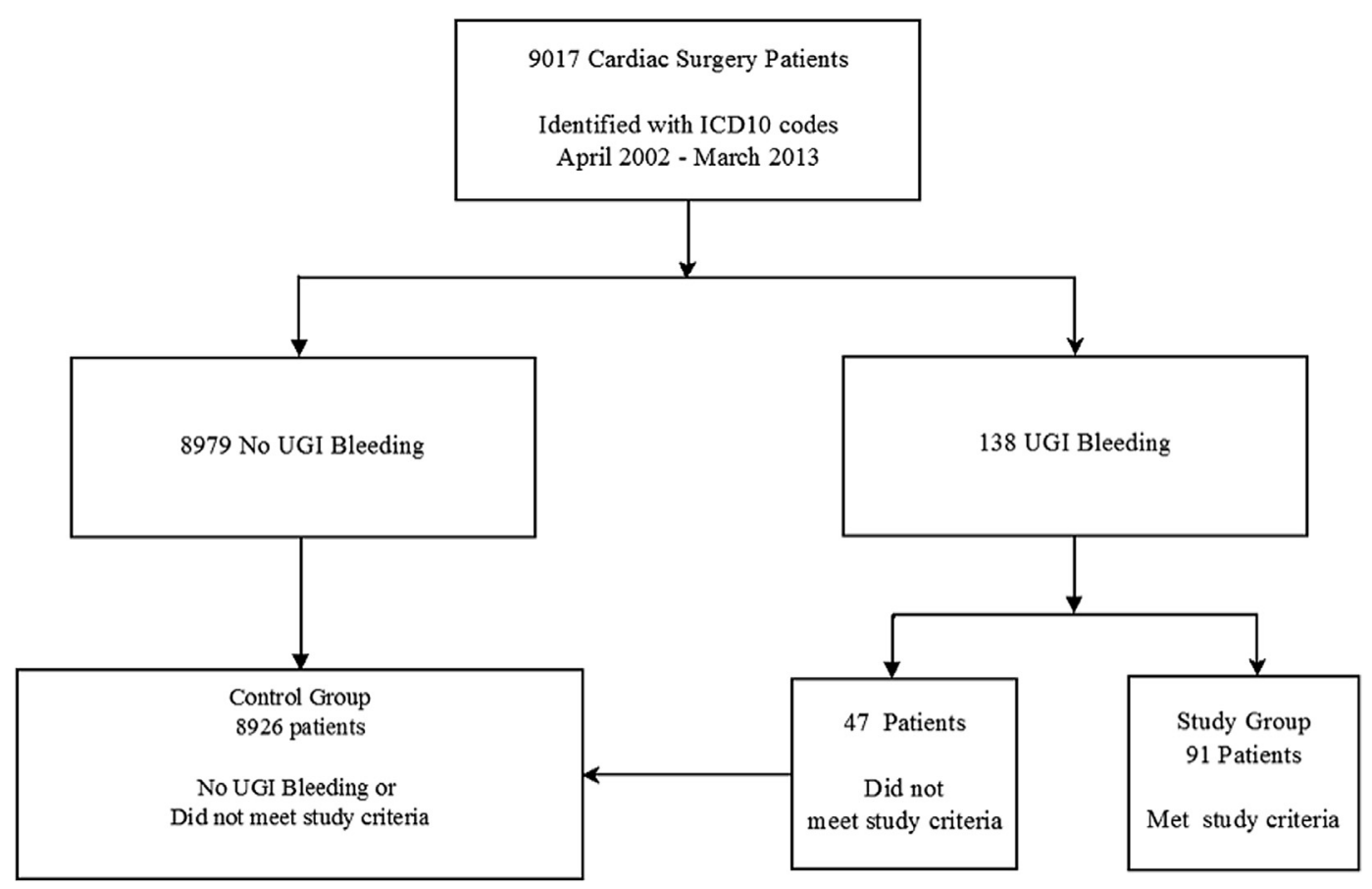

FIGURE 1. Diagram of patients included in study group and those who did not bleed or did not meet study criteria. ICD-10, International Classification of Diseases, 10th Revision; UGI, upper gastrointestinal. 
postoperatively. Patients who had a ventricular assist device also were excluded. At Foothills Medical Centre, patients are not administered preoperative GI prophylaxis routinely, although some were prescribed a proton pump inhibitor before surgery, at the discretion of the cardiac anesthesiologist performing the preoperative assessment. Postoperatively, GI prophylaxis was not part of routine postoperative management in the cardiovascular intensive care unit. Instead, practice focused on enhancing gut mucosal protection with the initiation of enteral feeds in those ventilated more than 24 hours postoperatively.

Data were collected from the administrative hospital discharge abstract database, which is a prospectively collected database at the Foothills Medical Centre that captures data from surgical records and discharge reports. It includes 25 fields with International Classification of Diseases, 10th Revision diagnosis codes, as well as diagnosis type indicators (main diagnosis, preexisting conditions, conditions acquired during hospitalization), admission and discharge dates, and demographic information. The patients who had postoperative GI bleeds were identified with International Classification of Diseases, 10th Revision codes. Also, the Alberta Provincial Project for Outcomes Assessment in Coronary Heart Disease database was used, which has been collecting detailed information on all patients undergoing coronary catheterization in Alberta since 1995. It includes patient demographics, clinical characteristics, and procedural details, which are then linked to data on clinical outcomes (revascularization procedures, myocardial infarction, length of stay, etc). The extracted data include demographics, preoperative comorbid conditions, perioperative variables, type of surgery, duration of cardiopulmonary bypass, crossclamp times, and postoperative complications. With the exception of ejection fraction, the Alberta Provincial Project for Outcomes Assessment in Coronary Heart Disease research database employs a validated method of using administrative data sources to fill in missing data.

Procedural data from endoscopy procedures were obtained from the endoPRO (Pentax Medical, Montvale, NJ) database, an electronic reporting software program that captures pathologic findings and procedural details from all endoscopies performed at the Foothills Medical Centre and surrounding hospitals in which endoscopy is performed. This information was used to confirm the diagnosis of GI bleeding, together with the characteristics and etiology of the bleeding lesion. In cases in which an endoscopic intervention was performed, details of the type of endoscopic procedure were recorded (ie, vessel clipping or epinephrine injection). Approval of the data analysis plan was obtained by submission to the institutional review board at the University of Calgary (project \# REB13-0365). Linkages between the databases were performed with the use of the patients' anonymous unique patient identification numbers.

\section{Statistical Analysis}

Data were summarized as counts with percentage, means \pm standard deviation, or median \pm interquartile range as appropriate. Univariate analyses for categorical variables were conducted with either the $\chi^{2}$ test or the Fisher exact test. The Student $t$ test or nonparametric Wilcoxon-Mann Whitney $U$ test was performed for continuous variables. Multivariate analysis was conducted with logistic regression. All variables deemed clinically relevant and statistically significant on univariate analyses stayed in the model, and no selection procedures were used. Multiple imputations were applied to ejection fraction, which had $14 \%$ missing values. We used the SAS fully conditional specification in proc mi to construct 10 imputed data sets that were used to obtain point and variance estimates in our logistic regression model. The odds ratio, corresponding to a $95 \%$ confidence interval, and the $P$ values are reported for each independent factor. Analyses were performed with SAS 9.4 (SAS Institute Inc, Cary, NC).

\section{RESULTS}

As is shown in Figure 1, a total cohort of 9017 patients underwent cardiac surgery during the 10-year study period.
One hundred thirty-eight patients were identified with postoperative GI bleeding. Of those, 91 met the study inclusion criteria of GI bleeding that required an endoscopy procedure for management. Of the 47 patients with GI bleeding who were excluded for not meeting inclusion criteria, 34 had preoperative bleeding, bleeding later than 30 days postoperative, or an endoscopy for reasons other than bleeding. An additional 13 patients were identified in the discharge abstract database as having GI bleeding but were excluded because they did not have an endoscopy. In most of these cases, the clinical evidence of bleeding was weak, or the bleeding was mild and the consulting gastroenterologist decided not to proceed with endoscopy. In 3 cases, the patient died of multiorgan failure before the endoscopy procedure could be performed. In one case, the patient's substitute decision maker refused consent for endoscopy.

Demographic and clinical characteristics of the study group (those that bled postoperatively) relative to the control group (those that did not bleed or were excluded) are shown in Table 1. The mean age of the 91 patients in the study group was $71 \pm 12.0$ years, which was older that the control group, at $66 \pm 11.5$ years. The study group was composed of mostly men $(76 \%)$ and only 22 were women $(24 \%)$. Valve surgery was more common, with $63 \%$ having a valve procedure and $37 \%$ having isolated coronary artery bypass grafting surgery $(P<.001)$. Congestive heart failure was more common in patients who bled $(34 \%$ vs $16 \% ; P<.001)$, and the time period of surgery was found to be significant.

In the study group, most GI bleeding occurred in the latter half of the 10-year study period, in years 2007 to $2012(P<.001)$. The variables of body mass index, sex, diabetes, hypertension, pulmonary disease, peripheral vascular disease, and crossclamp time were not found to be different between the 2 groups. When outcome variables were examined, length of hospital stay was found to be longer in the study group $(23.5 \pm 7.6$ vs $10.5 \pm 7.1$ days; $P<.001)$. Eight of the patients who had postoperative GI bleeding died, resulting in a 30-day mortality rate of $8.8 \%$ in the study group, compared with a mortality rate of $4.2 \%$ in the control group $(P=.03)$.

Analyses of the preoperative risk factors for GI bleeding are presented in Table 2 . The univariate analyses found that age older than 70 years was associated with postoperative GI bleeding. Also, a history of congestive heart failure, GI disease, cerebrovascular disease, chronic kidney disease, dialysis-dependent renal failure, or an ejection fraction $<35 \%$ was associated with bleeding $(P<.005)$. Patients taking Coumadin (Bristol Myers Squibb, New York, NY) before their operation were more likely to have GI bleeding postoperatively $(P=.01)$. A history of atrial fibrillation preoperatively also was found to be more prevalent in those who bled $(52 \%)$, relative to those who did not $(27 \%$; $P<.001)$. 
TABLE 1. Description of patient characteristics and outcome variables

\begin{tabular}{|c|c|c|c|c|c|}
\hline \multirow[b]{2}{*}{ Characteristics } & \multicolumn{2}{|c|}{ No postoperative bleeding, $n=8926$} & \multicolumn{2}{|c|}{ Postoperative bleeding, $\mathbf{n}=91$} & \multirow[b]{2}{*}{$P$ value } \\
\hline & $\mathbf{n}^{*}$ & No. $(\%)$ or mean \pm SD & $\mathbf{n}^{*}$ & No. $(\%)$ or mean \pm SD & \\
\hline \multicolumn{6}{|l|}{ Demographics } \\
\hline Age, y & 8926 & $66 \pm 11.5$ & 91 & $71 \pm 12.0$ & $<.001$ \\
\hline Female sex & 8926 & $2117(23.72)$ & 91 & $22(24.18)$ & .92 \\
\hline BMI, $\mathrm{kg} / \mathrm{m}^{2}$ & 8801 & $28.29 \pm 5.14$ & 88 & $28.29 \pm 6.02$ & .99 \\
\hline Diabetes & 8926 & $2311(25.89)$ & 91 & $28(30.77)$ & .29 \\
\hline Hypertension & 8926 & $5753(64.45)$ & 91 & $64(70.33)$ & .24 \\
\hline Congestive heart failure & 8926 & $1415(15.85)$ & 91 & $31(34.07)$ & $<.001$ \\
\hline Pulmonary disease & 8926 & $1677(18.79)$ & 91 & $19(20.88)$ & .61 \\
\hline Peripheral vascular disease & 8926 & $855(9.58)$ & 91 & $11(12.09)$ & .42 \\
\hline Surgery type & 8926 & & 91 & & $<.001$ \\
\hline Isolated CABG & & $5448(61.04)$ & & $34(37.36)$ & \\
\hline Valve procedure & & $3478(38.96)$ & & $57(62.64)$ & \\
\hline Surgery period & 8926 & & 91 & & $<.001$ \\
\hline $4 / 2002-3 / 2007$ & & $4694(52.59)$ & & $31(34.07)$ & \\
\hline $4 / 2007-3 / 2012$ & & $4232(47.41)$ & & $60(65.93)$ & \\
\hline Crossclamp time, $\min$ & 8380 & $65.7 \pm 35.3$ & 84 & $76.6 \pm 54.6$ & .07 \\
\hline Hospital stay, $\mathrm{d} \dagger$ & 8925 & $10.5 \pm 7.1$ & 91 & $23.5 \pm 7.6$ & $<.001$ \\
\hline 30-d mortality, d & 8926 & $379 \pm 4.25$ & 91 & $8 \pm 8.79$ & .03 \\
\hline
\end{tabular}

Table 3 presents the results of the multivariate analysis of preoperative variables. It shows that age greater than 70 years and a history of GI disease or atrial fibrillation were markers of postoperative GI bleeding. More recent surgery, during the period 2007 to 2012, also was found to be associated with bleeding. Those having isolated coronary artery bypass grafting surgery were less likely to bleed.

An additional comparison was done between the study group with the patients who did not meet the study criteria. Table 4 shows the results of that analysis. There was no difference in age, sex, body mass index, type of surgery, crossclamp time, or 30-day mortality. Unlike the study group that had more bleeds later in study period, there was no difference in bleeding rates between the 2002 to 2007 period and the 2007 to 2012 period. Mean hospital stay was longer in the study group relative to the patients who did not meet the study criteria (23.5 vs 19.23; $P<.001)$.

Analysis of endoscopy data was complete with reports on all study patients from the endoPro database with additional clinical details obtained by chart review. As is shown in Figure 2, it was found that $78 \%$ of all bleeds originated

TABLE 2. Univariate analyses of preoperative variables associated with postoperative GI bleeding

\begin{tabular}{|c|c|c|c|c|c|}
\hline \multirow[b]{2}{*}{ Factors } & \multicolumn{2}{|c|}{ No postoperative bleed, $n=8926$} & \multicolumn{2}{|c|}{ Postoperative bleed, $\mathrm{n}=91$} & \multirow[b]{2}{*}{$P$ value } \\
\hline & $\mathbf{n}^{*}$ & No. $(\%)$ & $\mathbf{n}^{*}$ & No. $(\%)$ & \\
\hline Ejection fraction & 7836 & & 79 & & $<.001$ \\
\hline$\geq 35 \%$ & & $5933(75.71)$ & & $45(56.96)$ & \\
\hline$<35 \%$ & & $441(5.63)$ & & $9(11.9)$ & \\
\hline Not reported on echo & & $1462(18.66)$ & & $25(31.65)$ & \\
\hline Coumadin & 8926 & $511(5.72)$ & 91 & $11(12.09)$ & .01 \\
\hline Cerebrovascular disease & 8926 & $712(7.98)$ & 91 & $15(16.48)$ & .003 \\
\hline Chronic kidney disease & 8926 & 419 (4.69) & 91 & $11(12.09)$ & .001 \\
\hline Congestive heart failure & 8926 & $1415(15.85)$ & 91 & $31(34.07)$ & $<.001$ \\
\hline Dialysis dependent renal failure & 8926 & $129(1.42)$ & 91 & $5(5.49)$ & .002 \\
\hline GI disease $\dagger$ & 8926 & $754(8.45)$ & 91 & $15(16.48)$ & .006 \\
\hline Atrial fibrillation & 8926 & $2452(27.47)$ & 91 & $47(51.65)$ & $<.001$ \\
\hline Age $\geq 70$ y & 8926 & $3524(39.48)$ & 91 & $59(64.84)$ & $<.001$ \\
\hline Diabetics & 8926 & $2311(25.89)$ & 91 & $28(30.77)$ & .29 \\
\hline Hypertension & 8926 & $5753(64.45)$ & 91 & $64(70.33)$ & .24 \\
\hline Pulmonary disease & 8926 & 1677 (18.79) & 91 & $19(20.88)$ & .61 \\
\hline Peripheral vascular disease & 8926 & $855(9.58)$ & 91 & $11(12.09)$ & .42 \\
\hline
\end{tabular}

GI, Gastrointestinal. *Patients with data available. †Defined as a history of esophageal varices, gastric or duodenal ulcer, or peptic ulcer disease. 
TABLE 3. Multivariate analysis of predictors of GI bleeds

\begin{tabular}{lcc}
\hline \multicolumn{1}{c}{ Characteristic } & Odds ratio & $\mathbf{9 5 \% ~ C I ~}$ \\
\hline Age $\geq 70$ y & 2.22 & $1.42-3.46$ \\
Surgery type CABG & 0.59 & $0.36-0.95$ \\
Surgery period 4/2007-3/2012 & 2.13 & $1.36-3.32$ \\
Coumadin & 1.09 & $0.55-2.16$ \\
Cerebrovascular disease & 1.63 & $0.91-2.90$ \\
Chronic kidney disease & 1.24 & $0.55-2.79$ \\
Congestive heart failure & 1.53 & $0.94-2.48$ \\
Dialysis dependent renal failure & 2.68 & $0.87-8.24$ \\
GI disease & 1.83 & $1.03-3.24$ \\
Atrial fibrillation & 1.96 & $1.24-3.11$ \\
Ejection fraction* & & \\
$\quad \geq 35 \%$ & 0.46 & $0.21-1.00$ \\
Not reported on echo & 0.56 & $0.24-1.31$ \\
\hline
\end{tabular}

$C I$, Confidence interval; $C A B G$, coronary artery bypass grafting; $G I$, gastrointestinal. *Multiple imputations were used for missing values.

from an upper GI source. Analysis of the etiology, illustrated in Figure 3, determined that the majority of upper GI bleeds were related to a duodenal ulcer $(71 \%)$, whereas other bleeding lesions included gastric ulcer (17\%), gastric erosion $(8 \%)$, duodenal erosion (3\%), and Mallory-Weiss tear $(1 \%)$. The bleeding source was not identified in $8 \%$ of patients. If an interventional procedure on the bleeding lesion was deemed necessary, this most commonly was accomplished with a combination of bipolar cautery, submucosal injection of dilute epinephrine, and/or hemostatic clipping (Video 1). Because of the practice patterns of the gastroenterologic endoscopists, gastric biopsies were performed rarely, and the presence of $H$ pylori was not determined at endoscopy. Instead, the gastroenterologists administered empiric $H$ pylori-eradication treatment as standard practice, given the high association of gastric and duodenal ulceration with $H$ pylori infection.
The overall incidence of bleeding that met the study criteria was $1.01 \%$. During the study period, the incidence of bleeding was found to increase over time. As is shown in Figure 4, incidence increased from $0.75 \%$ in 2002 to $1.95 \%$ in $2011(P=.006)$. The median duration to the bleeding episode was 10 days postoperatively (range 0-29), with $65 \%$ of GI bleeding episodes occurring between days 5 and 14.

\section{DISCUSSION}

The overall incidence of postoperative GI bleeding was found to be $1.01 \%$, which is lower than many previous reports; however, it is consistent with our strict inclusion criteria that required patients to have endoscopy. As a result, our overall incidence of all bleeding is likely underestimated. Smaller bleeds, treated with medical therapy alone, were not included in the study group. Patients who did meet the inclusion criteria had an upper GI bleeding source in $78 \%$. The lesion causing the bleed was identified as duodenal ulceration in $71 \%$. This finding contradicts the belief that most GI bleeding after cardiac surgery is stress-related mucosal breakdown causing gastritis or gastric erosions. ${ }^{14,21}$

This is a relevant finding because previous studies have not had the benefit of a robust endoscopy database. A previous large retrospective analysis suggested $83 \%$ of patients who bled had a duodenal ulcer; however, only $0.4 \%$ of those patients had an endoscopy procedure to confirm the source. ${ }^{4}$ GI bleeding from duodenal ulcers in the general population most often is due to PUD, which is associated with a different pathologic mechanism than bleeding due to stress-related mucosal breakdown. It has been shown in the gastroenterology literature that $90 \%$ to $100 \%$ of patients with duodenal ulcers are infected with H pylori. ${ }^{17}$ Furthermore, patients who are infected have a

TABLE 4. Description of patient characteristics comparing patients who bled postoperatively with those who were identified as bleeders but did not meet the study criteria

\begin{tabular}{|c|c|c|c|c|c|}
\hline \multirow[b]{2}{*}{ Characteristic } & \multicolumn{2}{|c|}{ Postoperative bleed, $\mathrm{n}=91$} & \multicolumn{2}{|c|}{ Excluded patients not meeting study criteria, $n=47$} & \multirow[b]{2}{*}{$P$ value } \\
\hline & $\mathbf{n}^{*}$ & No. $(\%)$ or mean \pm SD & $\mathbf{n}^{*}$ & No. $(\%)$ or mean \pm SD & \\
\hline \multicolumn{6}{|l|}{ Demography } \\
\hline Age, y & 91 & $71 \pm 12.0$ & 47 & $69 \pm 0.76$ & .47 \\
\hline Female sex & 91 & $22(24.18)$ & 47 & $8(17.02)$ & .70 \\
\hline BMI, $\mathrm{kg} / \mathrm{m}^{2}$ & 88 & $28.29 \pm 6.02$ & 47 & $27.66 \pm 4.86$ & .54 \\
\hline Surgery type & 91 & & 47 & & .23 \\
\hline CABG & & $24(37.36)$ & & $23(48.93)$ & \\
\hline Valve procedure & & $57(62.64)$ & & $24(51.07)$ & \\
\hline Surgery period & 91 & & 47 & & .01 \\
\hline 4/2002-3/2007 & & $31(34.07)$ & & $27(57.45)$ & \\
\hline $4 / 2007-3 / 2012$ & & $60(65.93)$ & & $20(42.55)$ & \\
\hline Crossclamp time, $\min$ & 84 & $76.6 \pm 54.6$ & 44 & $79.22 \pm 46.82$ & .78 \\
\hline Hospital LOS, d & 91 & $23.5 \pm 7.6$ & 46 & $19.23 \pm 9.74$ & $<.001$ \\
\hline 30-d mortality, d & 91 & $8(8.79)$ & 47 & $8(17.02)$ & .14 \\
\hline
\end{tabular}

$S D$, Standard deviation; $B M I$, body mass index; $C A B G$, coronary artery bypass grafting; $L O S$, length of stay. *Patients with data available. 


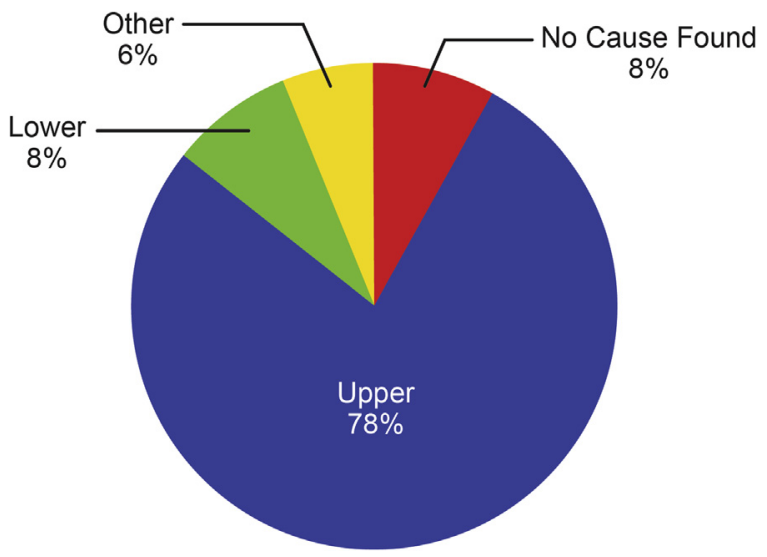

FIGURE 2. Endoscopic determination of bleeding location.

$10 \%$ to $20 \%$ risk of developing PUD, which represents a 3 - to 4-fold greater risk. . $^{19,20}$ For this reason, $H$ pylori-eradication therapy forms the principle strategy for medically managing PUD. Only 1 prospective study has incorporated testing for $H$ pylori in patients with GI bleeding after cardiac surgery. ${ }^{22}$ Although this study did not find an association between bleeding and $\mathrm{H}$ pylori infection, the small size of the series ( 26 patients) limits the generalizability of these findings.

Given the association of PUD and $H$ pylori, a preoperative test and treat strategy to eradicate the organism before surgery could have a significant impact on postoperative bleeding. There is experience with this strategy in the setting of nonsteroidal anti-inflammatory drug (NSAID) use, where a significantly reduced incidence of peptic ulcers at endoscopy was demonstrated in a group of patients who were tested and treated for $H$ pylori before starting longterm diclofenac. ${ }^{23}$ The background rate of $H$ pylori infection varies considerably, but older age, ethnicity, and country of origin are known to be associated with the incidence of infection. A Canadian study, relevant to our population, estimated the seroprevalence to be $23 \%$ of the general population. $^{24}$

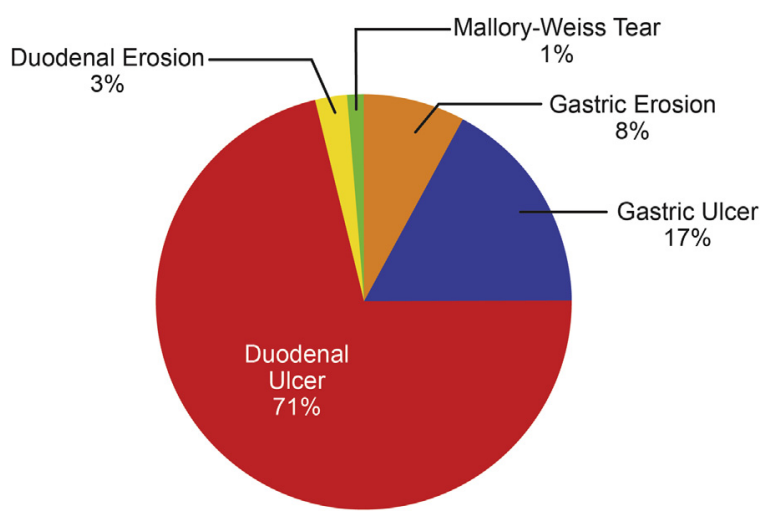

FIGURE 3. Endoscopic evidence of the etiology of the bleed.

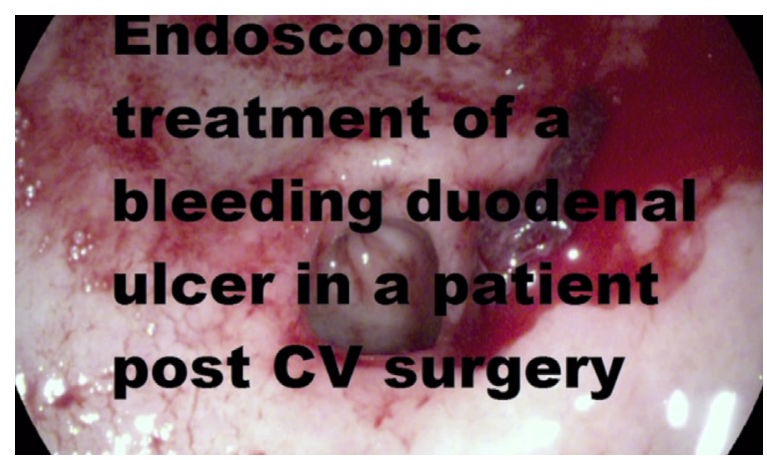

VIDEO 1. Endoscopic management of a bleeding duodenal ulcer after cardiac surgery. Video available at: http://www.jtcvsonline.org/article/ S0022-5223(17)30223-4/addons.

Several previous studies have suggested there are other preoperative risk factors that may predispose patients to bleeding after cardiac surgery. Advanced age, chronic aspirin or NSAID use, antiplatelet and anticoagulation use, cardiovascular disease, and preoperative hospitalization all have been identified. ${ }^{25-27}$ In the present study, age $>70$ years, ejection fraction $<35 \%$, congestive heart failure, cerebrovascular disease, chronic kidney disease, preoperative atrial fibrillation, and those undergoing valve procedures were found to be greater risk for bleeding. Surprisingly, postoperative anticoagulation with Coumadin was not found to be a risk factor for bleeding. Although speculative, this may have been due to conservative anticoagulation practices at our center, where anticoagulation is introduced slowly and patients tend to reach therapeutic levels of anticoagulation on or after discharge, when they are followed by an anticoagulation service. Also unexpected, prolonged mechanical ventilation in the intensive care unit was not found to be a risk factor for GI bleeding. That may be due

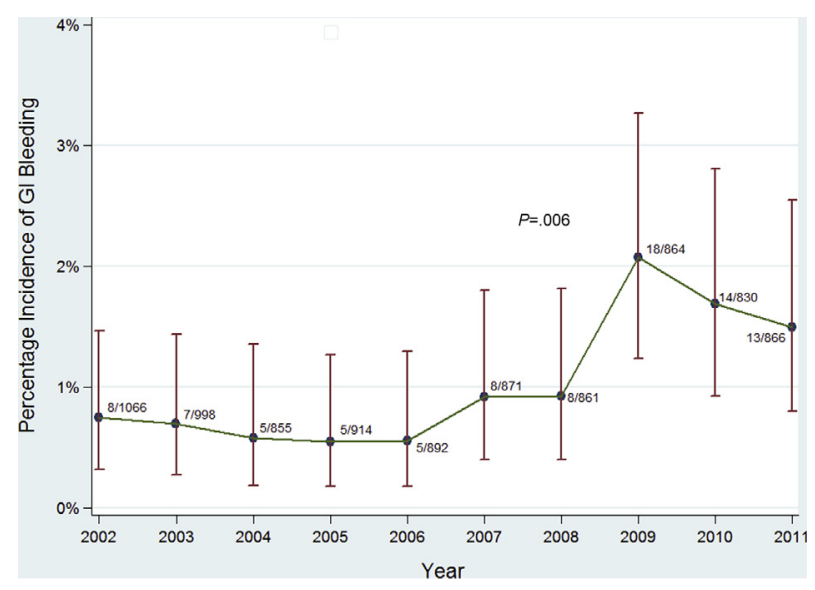

FIGURE 4. Incidence of postoperative GI bleeding over time. GI, Gastrointestinal. 
to the standard practice of enteral feeding with its mucosal protective effects, which is initiated within 24 hours in patients who remain intubated.

It is possible that a synergistic effect may be responsible for the majority of GI bleeds after cardiac surgery. Patients with preexisting subclinical PUD due to chronic $H$ pylori infection may bleed when exposed to other risk factors that lead to impairment of duodenal mucosal protective functions. It is known that GI mucosal defects arise from hemodynamic instability and are associated with splanchnic territory ischemia, which can occur during cardiac surgery. ${ }^{14}$ Perioperative hypotension, the use of vasoconstrictive agents, preexisting atherosclerotic vascular disease, low left ventricular ejection fraction, as well as prolonged cardiopulmonary bypass times have been identified previously as contributing factors. ${ }^{1,10,28}$ The probable mechanism involves mucosal hypoxia, reperfusion injury, and endotoxemia. ${ }^{14,29}$

In this study, postoperative GI hemorrhage was found to have an increasing incidence in cardiac surgery patients over time. The increasing incidence may be due to the increasing use of antiplatelet agents and direct oral anticoagulants. Other antithrombotic agents and gastrotoxic agents, such as NSAIDs, also may be more prevalent in today's more complex cardiac surgery patient population. Several trials have shown that the use of antithrombotic and antiplatelet agents in combination can increase the risk of GI bleeding. ${ }^{30,31}$ Combination agents, particularly dual antiplatelet therapy, were not common at our center before 2011 and therefore is unlikely, on its own, to account for the increasing incidence over time.

\section{Study Limitations}

Patients with GI bleeds were included in the study by identifying them retrospectively in a hospital administrative database. This practice has inherent limitations, because patients were identified with GI bleeds only if the diagnosis was attached to the chart when the patient was discharged or deceased. Given the risk of reporting error, some GI bleeding episodes may have been missed. Furthermore, we only included bleeds that required endoscopic intervention, and many smaller bleeds that resolved with medical management alone were not included.

\section{CONCLUSIONS}

The present data support existing evidence for preoperative risk factors that predispose patients undergoing cardiac surgery to postoperative GI bleeding. As a result, risk factor modification and initiation of prevention strategies, such as prophylaxis with gut mucosal protective medications, may be an important therapeutic intervention to reduce the incidence of bleeding. Furthermore, the majority of GI bleeding in our study was secondary to duodenal ulcers. Given the association of $H$ pylori infection with duodenal ulcers in the general population, a preoperative strategy to test and eradicate H pylori may prove beneficial. The authors are developing a prospective trial to investigate this possibility.

\section{Conflict of Interest Statement}

Authors have nothing to disclose with regard to commercial support.

The authors thank the personnel at the tertiary care sites for their diligence in data entry, which enabled this work to be completed. The authors thank the members of the Alberta Provincial Project for Outcomes Assessment in Coronary Heart Disease researchworking group.

\section{References}

1. Bolcal C, Iyem H, Sargin M, Mataraci I, Sahin MA, Temizkan V, et al. Gastrointestinal complications after cardiopulmonary bypass: sixteen years of experience. Can J Gastroenterol. 2005;19:613-7.

2. Geissler H, Fisher UM, Grunert S, Kuhn-Regnier F, Hoelscher A, Schwinger RH, et al. Incidence and outcome of gastrointestinal complications after cardiopulmonary bypass. Interac Cardio Vas Thorac Surg. 2006;5:239-42.

3. Viana F, Chen Y, Almeida AA, Baxter HD, Cochrane AD, Smith JA. Gastrointestinal complications after cardiac surgery: 10 year experience of a single Australian centre. ANZ J Surg. 2013;83:651-6.

4. Lebovics E, Lee SS, Dworkin BM, Heier SK, Casellas A, Reed G, et al. Upper gastrointestinal bleeding following open heart surgery. Dig Dis Sci. 1991;36: 757-60

5. Norton ID, Pokorny CS, Baird DK, Selby WS. Upper gastrointestinal hemorrhage following coronary artery bypass grafting. Aust N Z J Med. 1995;25:297-301.

6. Yilmaz A, Arslan U, Demirkilc E, Ozal E, Kuralay H, Bingol H. Gastrointestinal complications after cardiac surgery. Eur J Cardiothorac Surg. 1996;10:763-7.

7. Akpinar B, Sagbas E, Guden M, Kemertas K, Sonmez B, Bayindir O, et al. Acute gastrointestinal complications after open, heart surgery. Asian Cardiovasc Thorac Ann. 2000;8:109-13.

8. D’Ancona G, Baillot R, Poirier B, Dagenais F, de Ibarra JI, Bauset R, et al. Determinants of gastrointestinal complications in cardiac surgery. Tex Heart Inst $J$. 2003;30:280-5.

9. Jayaprakash A, McGrath C, McCullagh E, Smith F, Angelini G, Probert C. Upper gastrointestinal hemorrhage following cardiac surgery: a comparative study with vascular surgery patients from a single center. Eur J Gastroenterol Hepatol. 2004;16:191-4.

10. McSweeney ME, Garwood S, Levin J, Marino MR, Wang SX, Kardatzke D, et al Adverse Gastrointestinal complications after cardiopulmonary bypass: can outcome be predicted from preoperative risk factors? Anesth Analg. 2004;98:1610-7.

11. Filsoufi F, Rahmanian PB, Castillo JG, Scurlock C, Legnani PE, Adams DH. Predictors and outcome of gastrointestinal complications in patients undergoing cardiac surgery. Ann Surg. 2007;246:323-9.

12. Ait Houssa M, Selkane C, Moutaki Allah Y, Elbekkali Y, Amahzoune B, Wahid F, et al. Upper digestive bleedings after cardiac surgery. Ann Cardiol Angeiol (Paris). 2007;56:126-9.

13. Rodriguez R, Robich MP, Plate JF, Trooskin SZ, Sellke FW. Gastrointestinal complications following cardiac surgery: a comprehensive review. J Card Surg. 2010;25:188-97.

14. Van der Voort PH, Zandstra DF. Pathogenesis, risk factors, and incidence of upper gastrointestinal bleeding after cardiac surgery: is prophylaxis in routine bypass procedure needed? J Cardiothorac Vasc Anesth. 2000;14:293-9.

15. Aljarallah B, Wong W, Modry D, Fedorak R. Prevalence and outcome of upper gastrointestinal bleeding post-coronary artery bypass graft. Int $J$ Health Sci. 2008;2:69-76.

16. Amorim M, Barkman AN, Larocque M, Herba K, DeVarennes B, Martel M. Inhospital nonvariceal upper gastrointestinal bleeding following cardiac surgery: patient characteristics, endoscopic lesions and prognosis. Ulcers. 2012;201:1-6.

17. Kuipers EJ, Thijs JC, Festen HP. The prevalence of helicobacter pylori in peptic ulcer disease. Aliment Pharmacol Ther. 1995;9(2 suppl):59-69.

18. Liew WL, Walesby RK. Helicobacter pylori and upper gastrointestinal bleed in heart valve surgery. Eur J Cardiothorac Surg. 1998;13:637-40.

19. Malfertheiner P, Chan FK, McColl KE. Peptic ulcer disease. Lancet. 2009;374 $1449-61$. 
20. McColl KE. Pathopysiology of duodenal ulcer disease. Eur J Gastroenterol Hepatol. 2012;9(1 suppl):S9-12.

21. Oudemans-van Straaten HM, Jansen MD, Hoek FJ, Van Deventer SJ, Sturk A, Stoutenbeek CP, et al. Intestinal permeability, circulating endotoxin, and postoperative systemic responses in cardiac surgery patients. J Cardiothorac Vas Anesth. 1996;10:187-94.

22. Halm U, Halm F, Thein D, Mohr F, Mossner J. Helicobacter pylori infection: A risk factor for upper gastrointestinal bleeding after cardiac surgery? Crit Care Med. 2000;28:110-3.

23. Chan FK, To KF, Wu JC, Yung MY, Leung WK, Kwok T, et al. Eradication of Helicobacter pylori and risk of peptic ulcers in patients starting long-term treatment with non-steroidal anti-inflammatory drugs: a randomized trial. Lancet. 2002;359:9-13.

24. Naja F, Krieger N, Sullivan T. Helicobacter pylori infection in Ontario: prevalence and risk factors. Can J Gastroenterol. 2007:21:501-6.

25. Garcia-Rodriguez LA, Jick H. Risk of upper gastrointestinal bleeding and perforation associated with individual non-steroidal anti-inflammatory drugs. Lancet. 1994;343:769-72.

26. Terdiman JP, Ostroff JW. Gastrointestinal bleeding in the hospitalized patient: a case-control study to assess risk factors, causes, and outcome. Am J Med. 1998; 104:349-54.
27. Lanas A, Bajador E, Serrano P, Fuentes J, Carreno S, Gaurdia J, et al. Nitrovasodilators, low-dose aspirin, other nonsteroidal antiinflammatory drugs, and the risk of upper gastrointestinal bleeding. $N$ Engl J Med. 2000;343:834-9.

28. Zacharias A, Schwann TA, Parenteau GL, Riordan CJ, Durham SJ, Engoren M, et al. Predictors of gastrointestinal complications in cardiac surgery. Tex Heart Inst J. 2000;27:93-9.

29. Ait Houssa M, Atmani N, Nya F, Abdou A, Moutakiallah Y, Bamous M, et al. Stress gastric ulcer after cardiac surgery: pathogenesis risk factors and medical management. World J Cardiovas Dis. 2013;3:312-6.

30. Nikolsky E, Mehran R, Stone GW. Gastrointestinal bleeding in percutaneous coronary intervention and acute coronary syndromes. Am J Cardiol. 2009; 104(suppl):22C-9C.

31. Holster IL, Valkhoff VE, Kuipers EJ, Tjwa ET. New oral anticoagulants increase risk for gastrointestinal bleeding: a systematic review and meta-anaylsis. Gastroenterology. 2013;145:105-12.

Key Words: cardiac surgery, gastrointestinal hemorrhage, peptic ulcer disease

Readers who found these articles interesting may also like to read the following papers found in recent and future issues of our sister publications, Seminars in Thoracic and Cardiovascular Surgery and Operative Techniques in Thoracic and Cardiovascular Surgery!

\section{Acquired: Perioperative Management}

Original Submission: The Effects of Steroids on Coagulation Dysfunction Induced by Cardiopulmonary Bypass: A Steroids in Cardiac Surgery (SIRS) Trial Substudy. Domenico Paparella. Semin Thoracic Surg 2016: In press.

Editorial Commentary: Steroids and Cardiopulmonary Bypass: a Never-ending Story. Thierry Carrel. Semin Thoracic Surg 2016: In press.

Original Submission: Controlled Exponentially Weighted Moving Average Chart in Cardiac Surgery: A Simulation Study Across 9 Italian Cardiac Centers Marco Moscarelli. Semin Thoracic Surg 2016:253-258.

Editorial Commentary: Statistical Process Control in Cardiac Surgery? Ask Your Doctor. Paul Kurlansky. Semin Thoracic Surg 2016:259-260.

Original Submission: Early Extubation: A Proposed New Metric. Todd C. Crawford. Semin Thoracic Surg 2016:290-299.

Editorial Commentary: Early Extubation: A Proposed New Metric or What Was First: The Egg or the Chicken? Thierry Carrel. Semin Thoracic Surg 2016:300-301. 